\title{
Article
}

\section{Inorganic Self-Organized Silica Aragonite Biomorphic Composites}

Alina E. Voinescu, Matthias Kellermeier, Björn Bartel, Anna M. Carnerup, Ann-Kristin Larsson, Didier Touraud, Werner Kunz, Lorenz Kienle, Arno Pfitzner, and Stephen T. Hyde

Cryst. Growth Des., 2008, 8 (5), 1515-1521• DOI: 10.1021/cg700692t • Publication Date (Web): 16 April 2008

\section{Downloaded from http://pubs.acs.org on April 23, 2009}
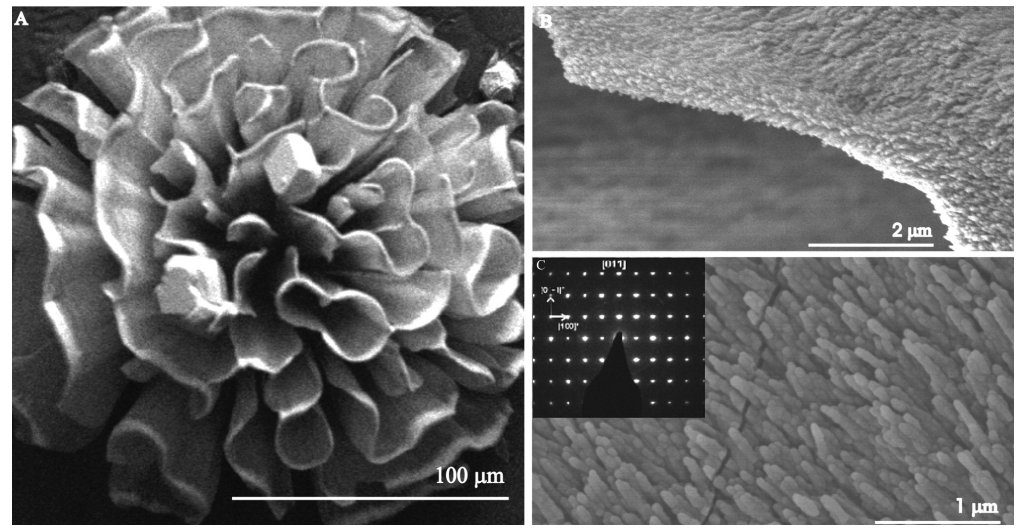

\section{More About This Article}

Additional resources and features associated with this article are available within the HTML version:

- Supporting Information

- Links to the 1 articles that cite this article, as of the time of this article download

- Access to high resolution figures

- $\quad$ Links to articles and content related to this article

- Copyright permission to reproduce figures and/or text from this article

\section{View the Full Text HTML}




\title{
Inorganic Self-Organized Silica Aragonite Biomorphic Composites
}

Alina E. Voinescu,$^{\dagger}$ Matthias Kellermeier, ${ }^{\dagger}$ Björn Bartel ${ }^{\dagger}$ Anna M. Carnerup, ${ }^{\dagger}$ Stephen T. Hyde*

Institute of Physical and Theoretical Chemistry and Institute of Inorganic Chemistry, University of Regensburg, D-93040, Germany, Department of Applied Mathematics, Research School of Physical Sciences, ANU, Australia, and Max Planck Institute for Solid State Research, Stuttgart, Germany

Received July 25, 2007; Revised Manuscript Received November 25, 2007

\begin{abstract}
The precipitation of calcium carbonate in alkaline silica solutions results in the formation of complex curvilinear forms if aragonite formation is encouraged by growth at an elevated temperature $\left(80^{\circ} \mathrm{C}\right)$. The resulting coralline self-assembled silica-calcium carbonate particles are "biomorphs", bearing a striking resemblance to natural coral forms. These materials, comprised of calcium carbonate nanocrystals and an amorphous silica matrix, have a complex ultrastructure, made of clusters of gathered sheets of variable curvatures formed by successive curling. The nanocrystals within these "ruled surfaces" are thin, elongated, densely packed needles of aragonite. These clusters are outgrowths from central saddlelike cores that resemble developable petaloid surfaces. The size, shape, crystallography, and chemical composition of the resulting biomorphs were examined by optical microscopy, field emission scanning electron microscopy (FE-SEM), powder X-ray diffractometry (XRD), Fourier transform infrared spectroscopy (FT-IR), transmission electron microscopy (TEM and HRTEM), and energy dispersive X-ray analysis (EDX).
\end{abstract}

\section{Introduction}

Biomorphs are inorganic, self-assembled silica-carbonate aggregates showing a wide range of noncrystallographic, biomimetic morphologies and sizes. ${ }^{1}$ Their forms include curvilinear sheets, helical filaments, braids, and floral spherulites, accompanied by the packing of crystalline rods within the selfassembled aggregates. They exhibit a complex structural hierarchy from the nano to optical scales, composed of nanometer-sized carbonate crystals, densely packed with orientational ordering between crystallographic axes of adjacent rods.

To date, these aggregates were found when barium and strontium carbonates were precipitated in basic silica solution into which atmospheric carbon dioxide was allowed to diffuse, forming witherite and strontianite phases, respectively. ${ }^{1}$ Until now, the precipitation of calcium in basic silica has not produced the curvilinear forms characteristic of biomorphs. ${ }^{2} \mathrm{CaCO}_{3}$ is often the most abundant chemical in sedimentary rocks and is widely used by nature as an inorganic component in exoskeletons and tissues of many mineralizing organisms, ${ }^{3}$ thus giving them strength and shape. ${ }^{4}$ Given the presence of calcium carbonate polymorphs in many biominerals as well as the geochemical abundance of calcium relative to barium and strontium, the possibility of forming curvilinear sheets of silica-calcium carbonate biomorphs deserves further exploration.

We note that noncrystallographic morphologies have been observed previously for $\mathrm{CaCO}_{3}$ materials. Garcia-Ruiz reported the formation of fanlike "sheaf-of-wheat" aggregates of calcite grown in alkaline silica gels, ${ }^{5-7}$ under similar conditions to those used to grow helical filaments of barium and strontium biomorphs. Although these dendritic calcites are noncrystallographic, they do not exhibit curvilinear surfaces common to biomorphs. Terada et al. have grown morphologically complex aragonite-silica composites in the presence of silica but

* To whom correspondence should be addressed. Tel: +61-2-61254553. Fax: +61-2-61250732. E-mail: stephen.hyde@anu.edu.au.

Institute of Physical and Theoretical Chemistry, University of Regensburg.

* Research School of Physical Sciences.

$\$$ Max Planck Institute for Solid State Research.

"Institute of Inorganic Chemistry, University of Regensburg. preferentially with the addition of pregrown needlelike aragonite seed crystals. ${ }^{8}$ In this case, the constituent crystalloid units are aragonite fibers, coated with silica. Gower et al. reported unusual helical morphologies of $\mathrm{CaCO}_{3}$ (vaterite polymorph), somewhat reminiscent of biomorphs. These forms were grown in the presence of charged polypeptides ${ }^{9}$ with no added silica. Wang et al. ${ }^{10}$ synthesized complex "flower type" vaterite superstructures in the presence of urea at high temperatures. Kulak et al. ${ }^{11}$ reported a variety of $\mathrm{CaCO}_{3}$ particles of varying crystallinity in the presence of two double-hydrophilic block copolymers. Walsh et al. ${ }^{12}$ described a method for synthesizing hollow porous shells of crystalline aragonite that resemble the coccospheres of certain marine algae. Mann reported sponge-like hollow vaterite spheroids, obtained from oil-water-surfactant microemulsions supersaturated with calcium bicarbonate. ${ }^{13}$ Gao et al. ${ }^{14}$ demonstrated that a hydrophobic polymer can induce the growth of $\mathrm{CaCO}_{3}$ microrings in aqueous solution. The formation of non-crystallographic $\mathrm{CaCO}_{3}$ morphologies have been recently reviewed. ${ }^{15,16}$ Such biomimetic noncrystallographic aggregates are necessary for understanding biomineralization processes.

Here, we report the formation of silica-calcium carbonate biomorphs, which develop into "coralline" composites through spontaneous self-assembly without the presence of organic additives (apart from the silica source) or seed crystals. The resulting biomimetic aggregates are able to form surfaces with variable curvatures by successive curling. These biomorphs display structural features over a range of length scales that are similar to previously reported barium and strontium examples. However, to date less morphological variety has been found in calcium biomorphs than in the barium or strontium counterparts.

\section{Experimental Section}

2.1. Materials and Sample Preparation. Tetraethylorthosilicate (purity $>98 \%$ ), calcium chloride dihydrate (purity $>99 \%$ ), and sodium hydroxide $(\mathrm{NaOH}$, purity $99 \%)$ were purchased from Sigma-Aldrich and used without further purification. Ethanol $(\mathrm{EtOH})$ was purified by distillation before use. Purified water with an electrical conductivity of less than $10^{-6} \mathrm{~S} \mathrm{~m}^{-1}$ was taken from a Milli-Q system. 
Alkaline silica solutions were prepared in a $100 \mathrm{~mL}$ plastic beaker by mixing $0.17 \mathrm{~mL}$ of tetraethylorthosilicate (TEOS), $0.17 \mathrm{~mL}$ of ethanol, $7.5 \mathrm{~mL}$ of $\mathrm{NaOH}(0.1 \mathrm{M})$, and water and stirring for $60 \mathrm{~min}$. The $\mathrm{pH}$ was adjusted to $11 \pm 0.1$. The reaction was started by adding different amounts $(0.25-1.5 \mathrm{~mL})$ of $0.5 \mathrm{M}$ calcium chloride solution. The total amount of the mixture was $100 \mathrm{~mL}$. After the addition of calcium salt, the solutions were then transferred to open cells [plastic circular wells (Linbro Tissue Culture), $1.7 \mathrm{~cm}$ deep and $1.6 \mathrm{~cm}$ in diameter] and warmed to $80{ }^{\circ} \mathrm{C}$ for about $6 \mathrm{~h}$. We emphasize the importance of the aforementioned experimental procedure (i.e., the mixing of alkaline silica solution with calcium chloride solution at 20 ${ }^{\circ} \mathrm{C}$ and then warming the mixture to $80{ }^{\circ} \mathrm{C}$ ) to take account of two different effects: First, working at $20^{\circ} \mathrm{C}$, we avoided the increase in the rate of polymerization (that increases as the temperature increases ${ }^{17}$ ) upon mixing alkaline silica solution with calcium chloride solution, and second, by warming to $80^{\circ} \mathrm{C}$, we favored aragonite formation over other $\mathrm{CaCO}_{3}$ polymorphs. ${ }^{18}$ After $6 \mathrm{~h}$, precipitation and growth of biomorphs occurred, due to the slow diffusion of atmospheric $\mathrm{CO}_{2}$ into the mixture. The products were then washed several times in water and ethanol and examined by optical microscopy and Au/Pd coated for field emission scanning electron microscopy (FE-SEM).

2.2. Analytical Methods. The $\mathrm{pH}$ of the TEOS-hydrolyzed solutions before and after the addition of calcium chloride solution were measured using an $\mathrm{Ag} / \mathrm{AgCl}$ plastic-body electrode (TPS, model smartCHEM-Laboratory).

2.3. Optical Microscopy. Optical microscopy was used to determine the crystal habit of the silica-calcium carbonate crystals. Light microscopy was performed using Nikon transmission microscope (model Eclipse E400), and images were taken between cross polarizers and produced with a JVC CCD color video camera (model TKC1380). FE-SEM was performed using a microscope (Hitachi, model S4500) operating at $0.5-30 \mathrm{kV}$ equipped with "upper and lower" secondary electron detectors (Robinson, model Mk 6). The samples were coated with $\mathrm{Au} / \mathrm{Pd}$ in an Emitech sputter coater using a rotational stage. Scanning electron microscopy (SEM) was performed using either a microscope FEI Quanta 400 T or a Jeol JSM 840, both operating at $0.2-30 \mathrm{kV}$. The sample was coated with $\mathrm{Au}$ in an Polaron Equipment LTD sputter coater.

2.4. Crystal Polymorphism. X-ray diffraction (XRD) measurements were done using a STOE STADI P diffractometer (STOE \& $\mathrm{CIE})$ providing $\mathrm{Cu} \mathrm{K} \alpha 1$ radiation monochromated with a germanium single crystal $(\lambda=1.540598 \AA)$. Typical diffraction patterns were recorded in the range of $8^{\circ}<2 \theta<90^{\circ}$ at a scanning speed of $0.8^{\circ} \%$ min. Fourier transform infrared spectroscopy (FT-IR) was recorded on a Jasco FT-IR-610 spectrometer. The samples were mixed with $\mathrm{KBr}$ powder. Subsequently, the resultant mixture were ground for 3-5 min in an agate mortar and deposited on the sample holder. The spectra were recorded in reflection mode from 4000 to $400 \mathrm{~cm}^{-1}$ at a resolution of $2 \mathrm{~cm}^{-1}$. For transmission electron microscopy (TEM and HRTEM), the biomorphic aggregates were crushed into crystal fragments. The resultant crystals were suspended in ethanol. A fraction of the crushed crystals were placed onto a holey carbon grid. HRTEM was performed with a Philips CM30 ST electron microscope (300 kV, Laboratory 6 cathode, Gatan multiscan CCD camera). The multislice formalism ${ }^{19}$ was used for image simulations.

2.5. Chemical Composition. Energy dispersive X-ray (EDX) analysis was performed using an EDAX microanalyzer mounted on a FEI Quanta 400T scanning electron microscope at $15 \mathrm{kV}$. This analyzer was used to quantify the approximate composition of the "coralline" self-assembled silica-calcium carbonate before and after leaching the crystals in acidic medium.

\section{Results}

3.1. Histogram of $\mathrm{CaCO}_{3}$ Crystal Fractions as a Function of the $\mathrm{Ca}^{2+}$ Concentration. Distinct $\mathrm{CaCO}_{3}$ crystal morphologies form after $6 \mathrm{~h}$ of growth by varying the $\mathrm{CaCl}_{2}$ concentration from 2 to $7.5 \mathrm{mM}$, (Figure 1). These include "coralline" silica-calcium carbonate biomorphs, "floral dumbbells" biomorphs (Figure S1, 2, Supporting Information), dendrites, pseudohexagonal prisms. and spherulites. In the following, we describe and characterize the complex "coralline" self-organized morphology of silica-calcium carbonate.

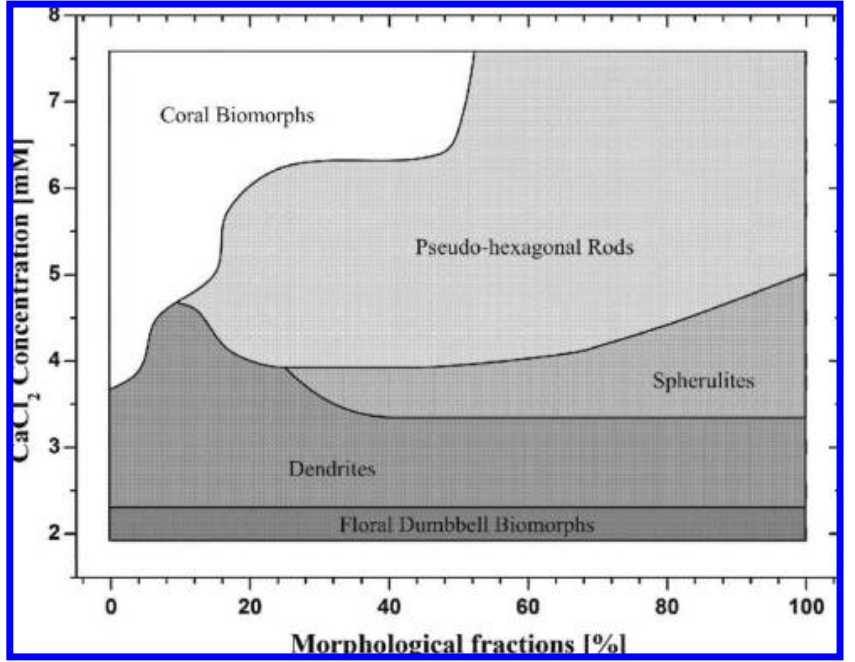

Figure 1. Schematic histogram of $\mathrm{CaCO}_{3}$ crystal fractions as a function of the $\mathrm{Ca}^{2+}$ concentration at $\mathrm{pH} 11$, obtained by averaging over many separate samples, incubated in separate runs. Given percentages are estimated values based on visual observation of (at least tens) of particles under polarized light.

3.2. Optical and Electron Microscopy. In the absence of silica, calcite rhombs and bundles of aragonite needles (Figure 2A) are obtained. The bundles of aragonite crystals are agglomerates of radially aligned needle-shaped single crystals. For small single crystal sizes, these aggregates had the appearance of spheres with the overall diameters around 30-50 $\mu \mathrm{m}$. In the presence of hydrolyzed TEOS solutions, these bundles suffer dramatic changes; the particles grown in alkaline silica solutions are "coralline" self-assembled silica-calcium carbonate biomorphs (Figure 2B).

The "Coralline biomorphs" are composed of sheetlike petaloid structures with almost zero Gaussian curvature (Figure 3A). These sheets resemble closely "developable" surfaces, swept out by the motion of a line along a generator spatial curve. The clusters are between 150 and $300 \mu \mathrm{m}$ in diameter, depending on their form. High-magnification FE-SEM imaging of the curvilinear sheet surfaces reveals the presence of thin (typically 50-100 nm in diameter), elongated densely packed nanometersized crystallites that grow parallel to the surface (see Figure $3 \mathrm{~B}, \mathrm{C})$. To further identify the chemical composition in whole composites, we measured the EDX spectra of several clusters. The spectra (Figure S3, Supporting Information) were consistent with the presence of $\mathrm{Si}, \mathrm{Ca}, \mathrm{C}$, and $\mathrm{O}$. The EDX data suggest that the calcium coralline biomorphs contain more silica (30-45\% Si, that is, the fractions of $\mathrm{Si}$ atoms out of the total calcium atom count) than the helical filaments $(5-10 \% \mathrm{Si})$, previously grown in the presence of barium. ${ }^{20}$ This measurement is supported by optical imaging that reveals greater transparency in calcium "coralline" biomorphs than in helicoidal microfilaments. It is worth noting that the clusters have flat faces (see Figures 3D,E) where the nucleation start point and the first sheetlike projections can be observed. This three-dimensional crystal morphology has also been observed in strontium ${ }^{21}$ and barium $^{22}$ carbonate biomorphs and bears a striking resemblance to natural corals (Figure 3H).

3.3. Leaching Experiments. Immersion of the biomorphs (Figure 3F) in $0.1 \mathrm{M}$ hydrochloric acid (dissolving all carbonate material) leaves a hollow silica "ghost" (Figure 3G). The surface texture of the leached particles is presented in the Figure 4. First, we observed that the overall structure is kept intact after leaching in the acidic medium. Second, the thin densely 


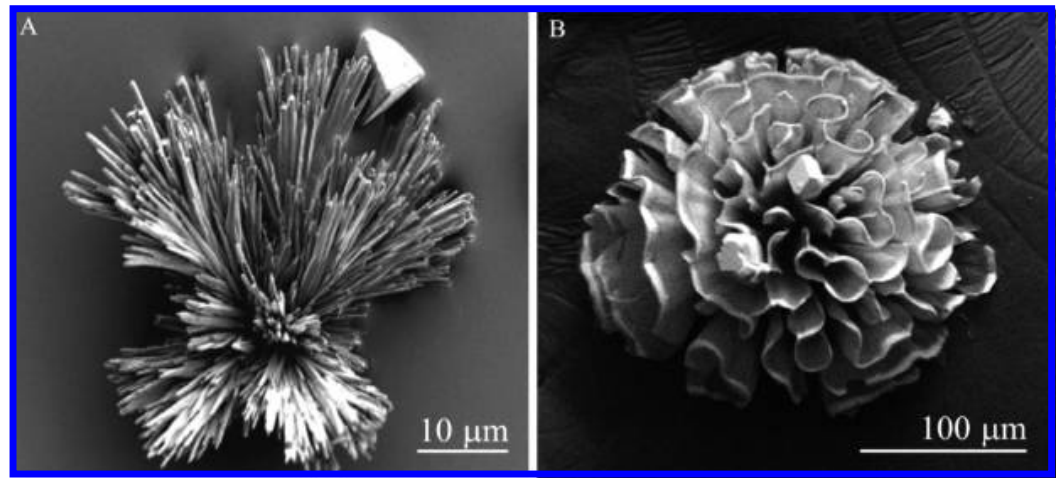

Figure 2. SEM images of a cluster precipitated in the absence (A) and in the presence (B) of silica sols.
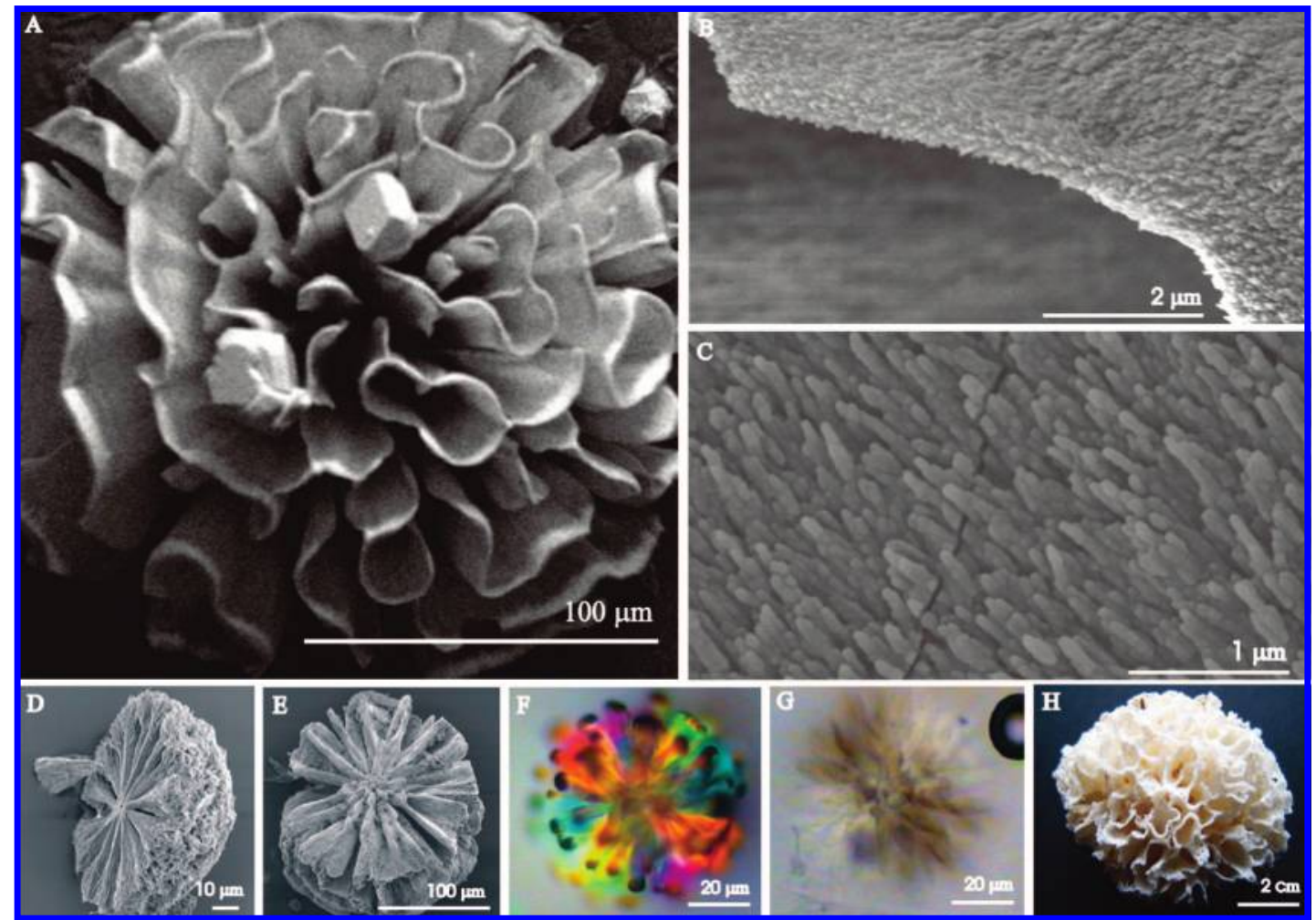

Figure 3. (A) Self-assembled "coralline" silica-calcium carbonate biomorphs. (B,C) High-magnification image of "coralline" silica-calcium carbonate showing the orientational ordering of crystallites. (D,E) Different positions of the silica-carbonate composites showing the starting point of nucleation and the orientation of the sheets. (F) Optical micrograph of silica-calcium carbonate aggregates, viewed between crossed polarizers. (G) Carbonate dissolution from the carbonate-silica material, leaving a silica "ghost". (H) Natural coral from the southeastern Australian seaside.

packed crystals are no longer seen in the surface texture, and third, the surface is not smooth. The curved surface is dominated by sinuous narrow striations (ridges). The EDX spectrum (Figure S4, Supporting Information) of this hollow silica skin left after immersion of the composites in the acidic medium $(0.1 \mathrm{M} \mathrm{HCl})$ is comprised of $\mathrm{Si}$ and $\mathrm{O}$ elements, and no $\mathrm{Ca}$ is found.

3.4. Influence of the Counterion. To ensure that the observed new morphology is not dependent on the nature of the calcium salt counterion $\left(\mathrm{Cl}^{-}\right)$, additional experiments were performed. $\mathrm{Cl}^{-}$was exchanged with $\mathrm{Br}^{-}$or $\mathrm{NO}_{3}{ }^{-}$, respectively, and precipitation was performed under the same conditions. Those experiments confirm that these structures do not depend on the nature of the calcium salt.

3.5. Crystal Polymorphism. Figure 5 shows the XRD pattern of the whole particles synthesized from the alkaline silica solution. The spectrum exhibits the characteristic reflections of aragonite $\left(\mathrm{A}_{111}, \mathrm{~A}_{121}\right.$, and $\left.\mathrm{A}_{021}\right)$ and calcite $\left(\mathrm{C}_{104}\right)$ phases. Furthermore, the XRD spectrum displays a very broad line with a maximum at $2 \theta$ about $15^{\circ}$ indicative of the presence of amorphous $\mathrm{SiO}_{2}$ and a diffraction peak at $38.93^{\circ}$, which could not be identified by comparison with reference diffraction patterns. It is likely that this phase is a ternary $\mathrm{Ca}-\mathrm{Si}-\mathrm{O}$ phase.

To gain information about the crystal polymorphism of the coralline structures, FT-IR analysis was performed (Figure 6). Comparison of the bands at $713,855,1092$, and $1486 \mathrm{~cm}^{-1}$ with standard IR spectra of aragonite type calcium carbonate [the symmetric stretch $\left(v_{4}\right)$ at $713 \mathrm{~cm}^{-1}$, a broad absorption of the carbonate out-of-plane bending peak $\left(v_{2}\right)$ at $854 \mathrm{~cm}^{-1}$, the symmetric stretch $\left(v_{1}\right)$ at $1080 \mathrm{~cm}^{-1}$, and a peak $\left(v_{3}\right)$ of the asymmetric stretch of the carbonate ion at 1488 and 1440 $\left.\mathrm{cm}^{-1}\right],{ }^{23,24}$ suggests that the structure contains the aragonite calcium carbonate crystal phase. Along with the aragonite bands, the spectrum reveals bands at $467,799,859$, and $1654 \mathrm{~cm}^{-1}$ 


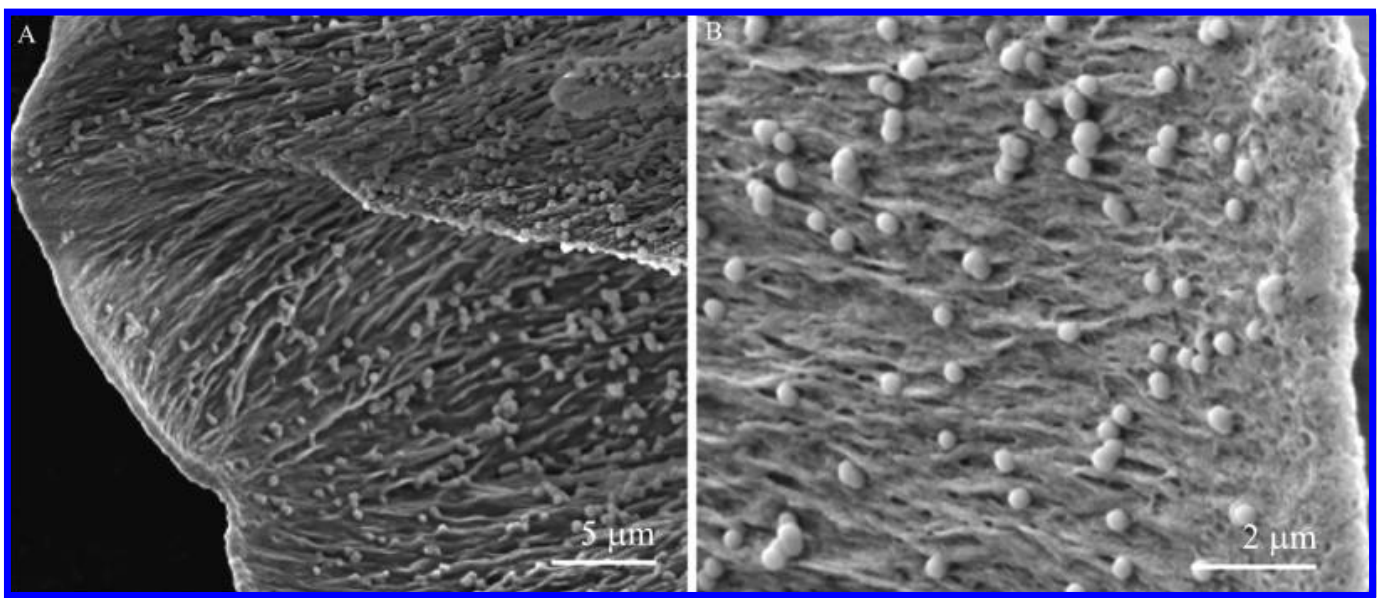

Figure 4. High-magnification FESEM images of biomorphs (after acidic leaching of carbonate) showing the silica skeleton. The small spheres may be an artifact of secondary deposition rather than intrinsic components of the biomorph during growth.

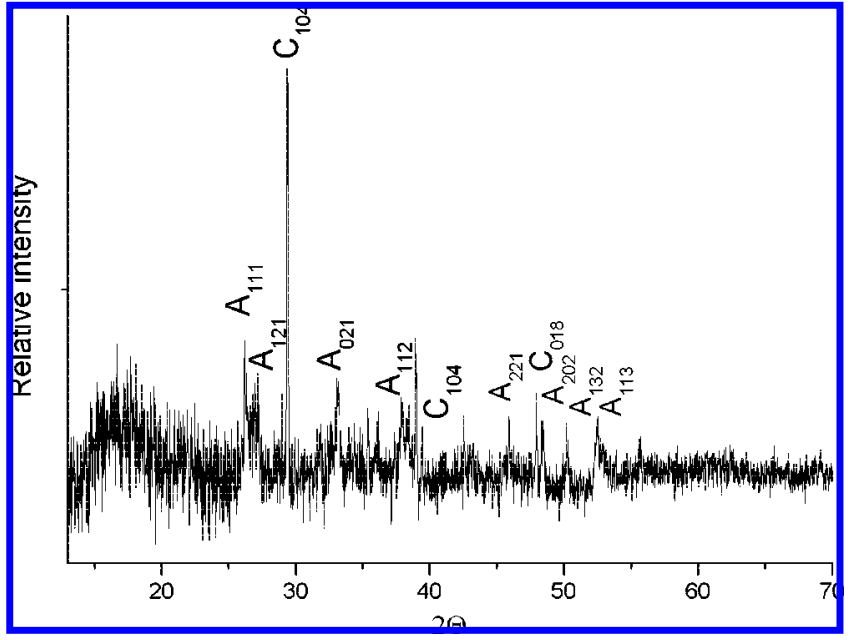

Figure 5. XRD spectrum of the self-assembled silica-calcium carbonate.

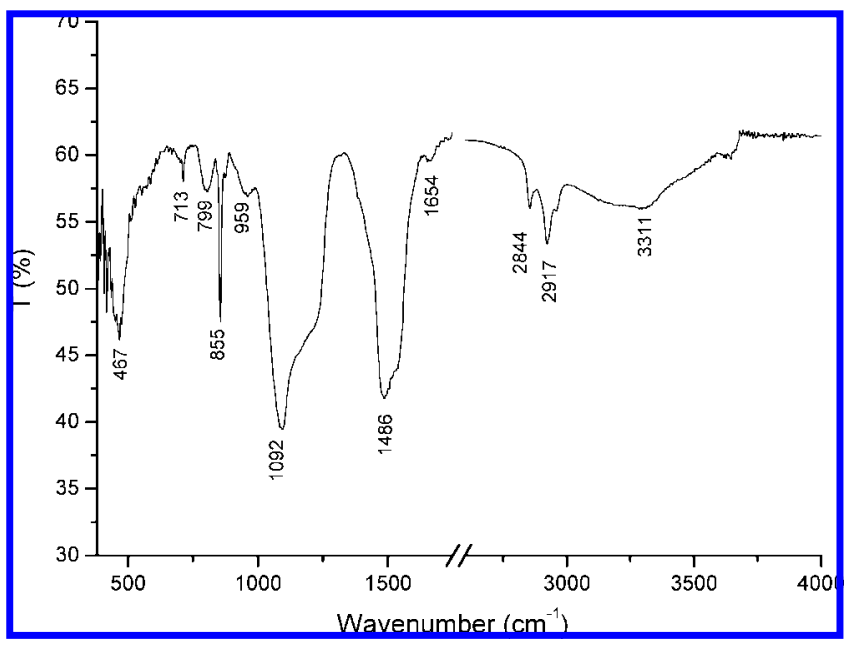

Figure 6. FT-IR spectrum of the self-assembled silica-calcium carbonate.

attributed to silica: ${ }^{25}$ namely the bending vibration, symmetric stretching, $\mathrm{Si}-\mathrm{O}-\mathrm{Si}$ asymmetric stretching, and the $\mathrm{Si}-\mathrm{OH}$ stretching modes, respectively. Bands in the range of 2000-3500 $\mathrm{cm}^{-1}$ are likely to be caused by $\mathrm{OH}^{-}$and water vibrations.
According to TEM observations of small crystals deposited on a carbon film, the needlelike aragonite crystals (Figure 7B) coexist with amorphous silica spheres (Figure 7A) and amorphous $\mathrm{Ca}-\mathrm{Si}-\mathrm{O}$ particles. Figure $7 \mathrm{C}$ shows a typical selected area electron diffraction (SAED) pattern recorded on the needle shown in Figure 7B. The sharp Bragg reflections can be indexed to the orthorhombic lattice of aragonite (zone axis [011]). Tilting experiments support this carbonate phase assignment (Figure 7D-F). EDX analyses of the needles show the presence of $\mathrm{Ca}$, $\mathrm{C}$, and $\mathrm{O}$ exclusively. Twinning or other kinds of microsized defects was never observed. HRTEM was used to probe for nanoscale crystal defects. A close analysis of several needles underlines their single crystalline nature; see for instance Figure 7G,H for zone axes [101] and [011], respectively. The attached simulated micrograph was calculated on the basis of aragonite: the convincing agreement between experimental and simulated images confirms our assignment of these needles as aragonite.

These EDX, XRD, FT-IR, and TEM results all confirm, that these extraordinary structures are composed of calcium carbonate minerals in the form of an aragonite phase and a "silica matrix".

3.6. Morphogenesis of "Coralline" Particles. To get more information about the self-assembly process of "coralline" silica calcium carbonate, we have monitored the morphological evolution of the clusters (see Figure 8) for up to $6 \mathrm{~h}$. In these experiments, the reaction was stopped at different time intervals (every 30 min during $6 \mathrm{~h}$ ). During the first $2 \mathrm{~h}$, no "coralline" particles could be detected, but between 2 and $3 \mathrm{~h}$, isotropic skeletal architectures were seen between crossed polarizers. We note that the "coralline" shapes obtained after $6 \mathrm{~h}$ are anisotropic composites due to the presence of aragonite in the structure (Figure 3F). This difference in isotropy could be due to the thickness of the whole aggregate or to the presence of a (metastable) amorphous calcium carbonate.

The isotropic self-assembled silica-calcium carbonate clusters collected in the early stages of the precipitation occasionally present double layer surfaces (Figure 9). The external and internal (i.e., the surface between the double layer) surface textures of the particles are identical, and both show striations on the surface. During outgrowth, we infer that either these double layer sheets develop into opened conical subunits or they collapse to form one layer. 


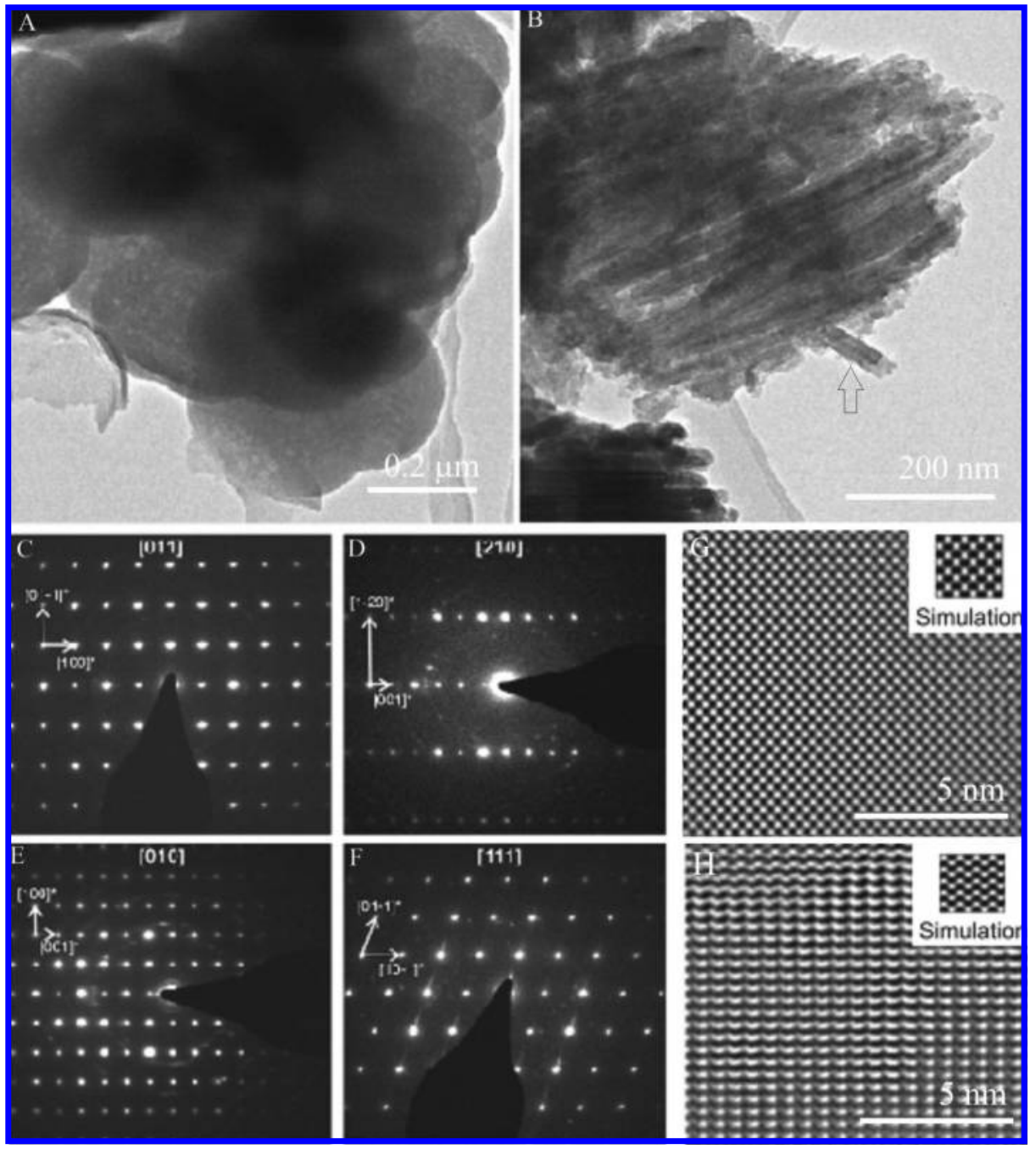

Figure 7. (A) TEM image of an amorphous silica particle with spherulitic morphology. (B) Densely packed nanometer-sized aragonite needles and $(\mathrm{C}-\mathrm{F})$ the corresponding SAED diffraction patterns of a single needle (see arrow), (G) HRTEM image (zone axis [101]) with simulated micrograph $(\Delta f=0 \mathrm{~nm}$; thickness, $2.8 \mathrm{~nm})$, and $(\mathrm{H})$ HRTEM image (zone axis [011]) with simulated micrograph $(\Delta f=10 \mathrm{~nm}$; thickness, $2.8 \mathrm{~nm})$.

\section{Discussion}

Biomorph syntheses were attempted in alkaline silica sols prepared by hydrolysis of tetraethyl orthosilicate (TEOS) over a range of temperatures. The addition of $\mathrm{CaCl}_{2}$ and subsequent diffusion of atmospheric $\mathrm{CO}_{2}$ into the solution results in the formation of carbonate. Experiments done at ambient temperature and pressure resulted mainly in calcite and failed to form biomorphs. ${ }^{26}$ Although $\mathrm{Ca}^{2+}$ is somewhat large for 6-fold coordination (calcite) by oxygen atoms, it is relatively small for 9-fold coordination (aragonite) at room temperature. Thus, the rate of transition from calcite to aragonite is a function of pressure and temperature. ${ }^{27}$ Previous work ${ }^{28}$ has shown that the relative abundance of calcium carbonate polymorphs is strongly influenced by the precipitation temperature; the higher the experimental temperature, the easier the formation of aragonite, due to enhanced kinetic stability. Therefore, because the aragonite structure seems to be crucial for biomorph formation, ${ }^{1}$ the experiments were performed at elevated temperature $\left(80{ }^{\circ} \mathrm{C}\right)$.

Experiments conducted at this temperature furnished complex self-assembled aggregates of silica-calcium carbonate, structured at three distinct length scales (atomic, meso, and micrometer scale), namely, "coralline" particles (Figures 2B). Such hierarchical building principles are well-known from biomin- erals, such as nacre. These calcium biomorphs do not display the structural variety at the micrometer scale found in their barium counterparts; in particular we have been unable to detect twisted filaments. ${ }^{1,2} \mathrm{We}$ note that precipitates grown under identical conditions in the absence of silica are conventional aragonite crystals (Figure 2A) and euhedral rhombohedral calcite.

The initial stage of these noncrystallographic particles is a "metal-silica matrix" in a colloidal state. The formation mechanism of this metal-silica matrix is, we think, the following. The $\mathrm{Ca}^{2+}$ ions are initially complexed with anionic silica oligomers in the solution. As the $\mathrm{pH}$ drops, the molecular mass of silica oligomers increases as they cross-link, building the matrix. During this condensation process, the silica charge becomes less negative, due to cross-linking. Over time, the solution becomes supersaturated in carbonate species. The partially silica-bound $\mathrm{Ca}^{2+}$ ions from the "metal-silica matrix" then combine with carbonate species and precipitate along the matrix, forming the silica-calcium carbonate composites. From our observations, it follows that these aggregates present a complex structure composed of calcium carbonate in form of an aragonite phase and a "silica matrix".

The SEM images suggest that the "coralline" clusters accreted from cores resembling hyperbolic ("saddles" 29 ) domains (Figure 


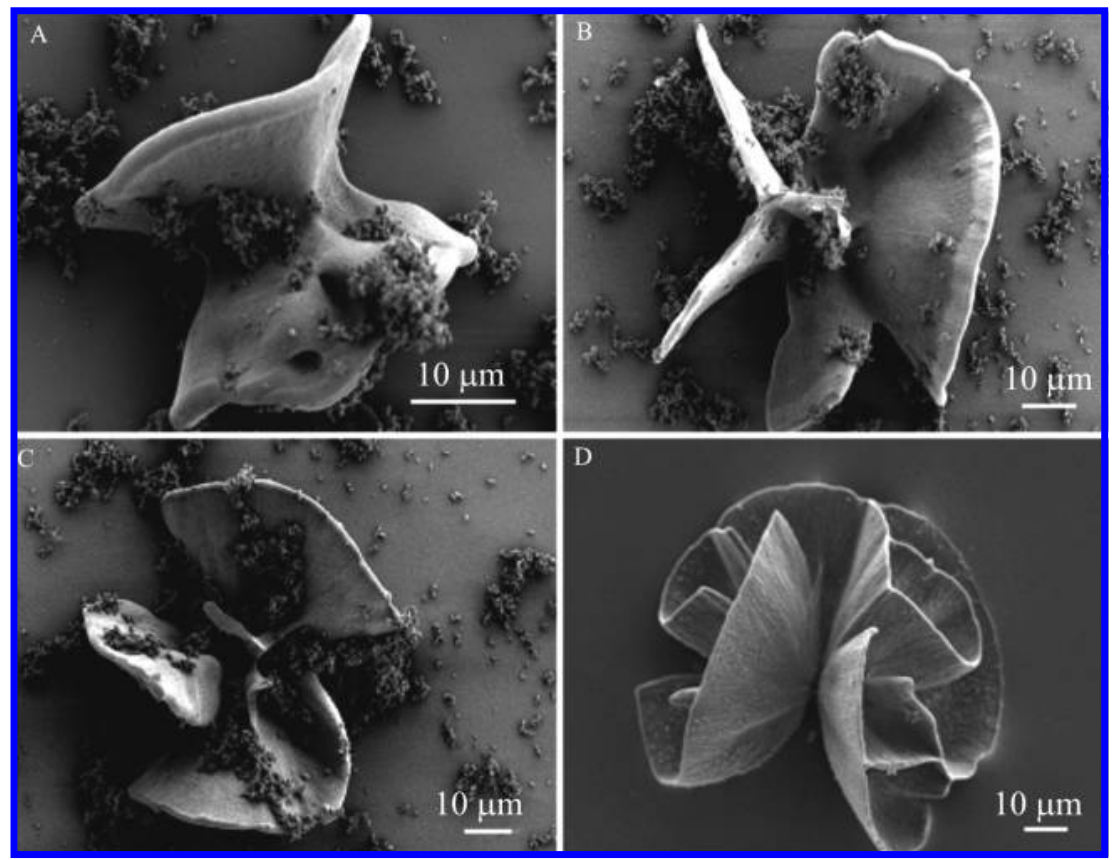

Figure 8. FE-SEM images of distinct self-assembled silica-calcium carbonate aggregates. The enhanced folding from A to D demonstrates the morphological evolution with time seen in some particles, although these images are not a time series of a single particle.

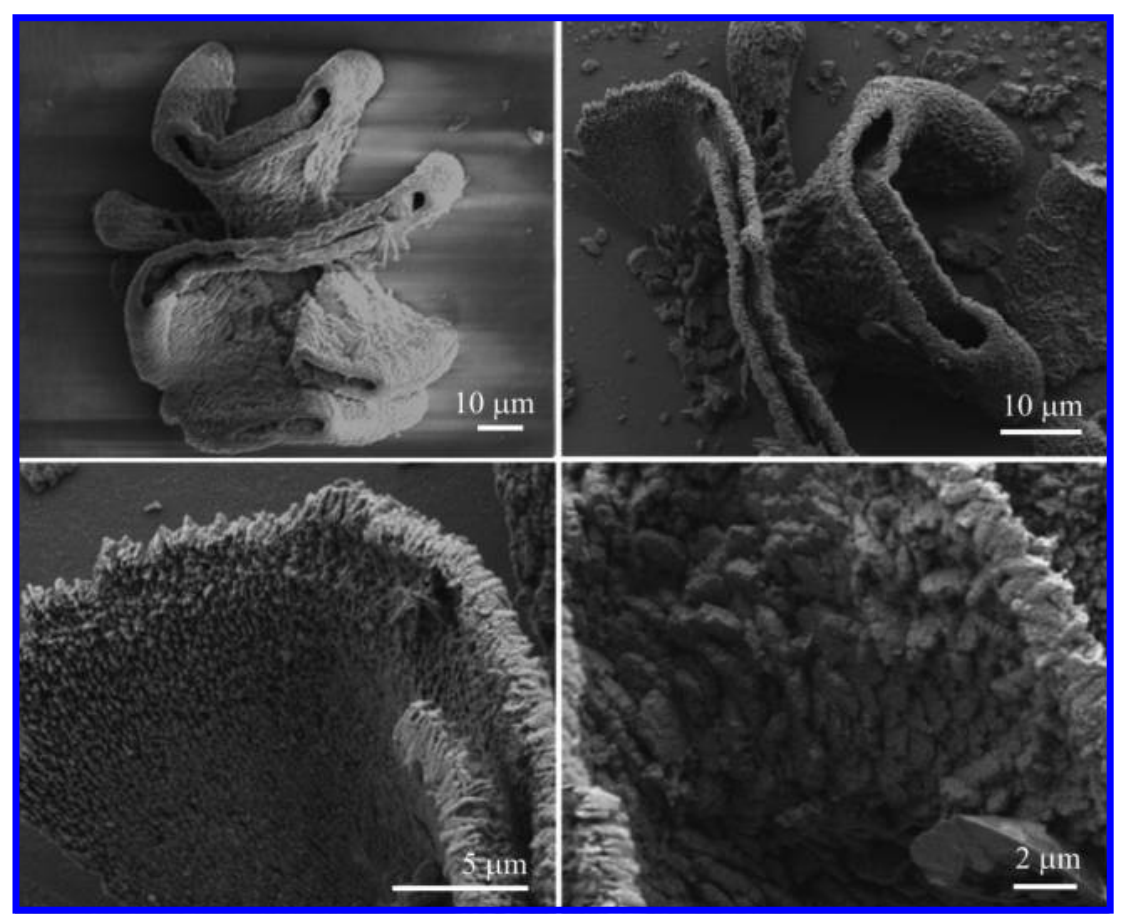

Figure 9. SEM images of self-assembled "coralline" silica-calcium carbonate collected after $3 \mathrm{~h}$ showing the surface texture of the particle.

$8 \mathrm{~A}$ ), followed by outgrowth to developable surfaces ("hats"30), perfectly recognized in Figure 8D. Developable surfaces are among the "ruled surfaces", that is, surfaces generated by displacement of a straight line along a space curve (the "generatrix"). A developable surface is a ruled surface having Gaussian curvature zero everywhere. The linear generatrices seem more or less evident in Figure 8D. When these lines are adjacent to the particle center (i.e., the oldest site), they curve gently, following a principal direction demarking the curves of minimal curvature on the directions of these generatrices (Figure $3 \mathrm{~A}$ and $8 \mathrm{D}$ ), or their curved extrapolations in the neighborhood of the center (Figure 8D). Clear lines are visible in Figure 3A, normal to the generatrices, reminiscent of striations that are seen in some shells in certain corals and in numerous crystals that grow by accretion.

There are some indications that the outer edges of the systems are slightly thickened (Figure 3A), avoiding excessive curvatures, which are energetically costly, and that the boundaries are rather weakly consolidated.

The complex ternary structure (mineral Ca-carbonate, organic matrix, and water ${ }^{31}$ ) which constitutes natural corals is found also in these aragonite-silica biomorphs, but with a fundamental distinction. Biomorphs are composed exclusively of inorganic matter. Nevertheless, the inorganic silica skeleton of the self- 
organized silica-calcium carbonate biomorphs seems to behave similarly to the organic skeleton of natural corals.

\section{Conclusions}

Self-assembled silica-calcium carbonate biomorphs were successfully grown in alkaline silica solutions prepared at 20 ${ }^{\circ} \mathrm{C}$ then warmed at $80{ }^{\circ} \mathrm{C}$ for $6 \mathrm{~h}$, to induce the formation of aragonite. These striking, hierarchically structured morphologies composed of curved sheetlike structures consist of orientationally ordered, nanometer-sized aragonite crystallites. The "coralline" clusters were seeded from hyperbolic ("saddles") domains, followed by further growth to form coalesced developable surfaces ("hats"). Two combined mechanisms lead to the formation of these "coralline" self-assembled silica-calcium carbonates: first, the building process in solution of "metal-silica matrix", which is composed of calcium ions and silica oligomers; second, the transport of carbonate ions inducing aragonite calcification. The precise role of aragonite in promoting calcium biomorph growth-though crucial-remains unknown.

Acknowledgment. We thank Prof. Dr. Yves Bouligand for his comments regarding the morphogenesis of "coralline" selfassembled silica-calcium carbonate. We thank Alois Lecker for recording the XRD spectrum.

Supporting Information Available: Self-assembled "floral dumbbell" silica-calcium carbonate and EDX spectra of "coralline" selforganized silica-calcium carbonate biomorphs. This material is available free of charge via the Internet at http://pubs.acs.org.

\section{References}

(1) Garcia-Ruiz, J. M.; Hyde, S. T.; Carnerup, A. M.; Christy, A. G.; Van Kranendonk, M. J.; Welham, N. J. Science 2003, 302, 1194.

(2) Garcia-Ruiz, J. M.; Carnerup, A. M.; Christy, A. G.; Welham, N. J.; Hyde, S. T. Astrobiology 2002, 2 (3), 353.

(3) Mann, S. Biomineralisation: Principles and Concepts in Bioinorganic Materials Chemistry; Oxford University Press: New York, 2001.

(4) Weiner, S.; Addadi, L. J. Mater. Chem. 1997, 7 (5), 689.
(5) Garcia-Ruiz, J. M. J. Cryst. Growth 1985, 73 (2), 251.

(6) Dominguez Bella, S.; Garcia Ruiz, J. M. J. Cryst. Growth 1986, 79 (1-3), 236.

(7) Dominguez Bella, S.; Garcia Ruiz, J. M. J.Mater. Sci. 1987, 22 (9), 3095.

(8) Imai, H.; Terada, T.; Miura, T.; Yamabi, S. J. Cryst. Growth 2002, 244, 200.

(9) Gower, L. A.; Tirrell, D. A. J. Crust. Growth 1998, 191, 153.

(10) Wang, L.; Sondi, I.; Matijevic, E. J. Colloid Interface Sci. 1999, 218 , 545.

(11) Kulak, A. N.; Iddon, P.; Li, Y.; Armes, S. P.; Coelfen, H.; Paris, O.; Wilson, R. N.; Meldrum, F. C. J. Am. Chem. Soc. 2007, 129 (12), 3729.

(12) Walsh, D.; Mann, S. Nature 1995, 377, 320.

(13) Mann, S. Angew. Chem. Int. Ed. 2000, 39, 3392

(14) Gao, Y.; Yu, S.; Cong, H.; Jiang, J.; Xu, A.; Dong, W.; Cölfen, H. $\underline{\underline{J}}$ Phys. Chem. B 2006, 110 (13), 6432.

(15) Cölfen, H. Top. Curr. Chem. 2007, 271, 1.

(16) Meldrum, F. C. Handbook of Biomineralization: Biomimetic and Bioinspired Chemistry; Wiley-VCH: Weinheim, 2007.

(17) Iler, R. K. The Chemistry of Silica: Solubility, Polymerisation, Colloid and Surface Proprieties, and Biochemistry; Wiley-Interscience: New York, 1979.

(18) Yu, J.; Lei, M.; Cheng, B.; Zhao, X. J. Crust. Growth 2004, 261, 566.

(19) Stadelmann, P. A. Ultramicroscopy 1987, 21, 131.

(20) Voinescu, A. E.; Kellermeier, M.; Carnerup, A. M.; Larsson, A. K.; Touraud, D; Hyde, S. T.; Kunz, W. J. Crust. Growth 2007, 306, 152.

(21) Terada, T.; Yamabi, S.; Imai, H. J. Crvst. Growth 2003, 353, 435.

(22) Hyde, S. T.; Carnerup, A. M.; Larson, A. K.; Christy, A. G.; GarciaRuiz, J. M. Phvsica A 2004, 339, 24.

(23) Falini, G.; Albeck, S.; Weiner, S.; Addadi, L. Science 1996, $271,67$.

(24) Anderson, F. A.; Brecevic, L. Acta Chem. Scand. 1991, 45, 1018.

(25) Martinez, J. R.; Ruiz, F.; Vorobiev, Y. V. J. Chem. Phys. 1998, 109, 751.

(26) Imai, H; Terada, T.; Yamabi, S. Chem. Commun. 2003, 4, 484.

(27) Klein, C.; Hurlbut, C. S. Manual of Mineralogy; Wiley: New York, 1993.

(28) Zhou, G. T.; Zheng, Y. F. J. Mater. Sci. Lett. 1998, 17, 905.

(29) Bouligand, Y. Liq. Crvst. 1999, 26 (4), 501.

(30) Bouligand, Y. J. Phvs. (Paris) 1980, 41, 1297.

(31) Dauphin, Y.; Cuif, J. P.; Massard, P. Chem. Geol. 2006, 231, 26.

CG700692T 